Rev. Bras. Saúde Prod. Anim., Salvador, v.13, n.3, p.694-700 jul./set., 2012 http://www.rbspa.ufba.br ISSN 15199940

\title{
Presença de Escherichia coli em fígados de frangos provenientes de matadouros avícolas
}

\author{
"Escherichia coli" presence in poultry livers from slaughterhouses
}

\author{
SILVA, Isabella de Matos Mendes da ${ }^{2 *}$; BALIZA, Marcílio ${ }^{2}$; SANTOS, Marcos \\ Pereira $^{2}$; REBOUÇAS, Larissa Tannus ${ }^{2}$; ROCHA, Édila Verônica da Silva ${ }^{2}$; SANTOS, \\ Vilmara Almeida dos ${ }^{2}$; SILVA, Ricardo Mendes da ${ }^{1}$; EVÊNCIO-NETO, Joaquim ${ }^{1}$ \\ ${ }^{1}$ Universidade Federal Rural de Pernambuco, Programa de Pós-Graduação em Ciência Veterinária, \\ Recife, Pernambuco, Brasil. \\ ${ }^{2}$ Universidade Federal do Recôncavo da Bahia, Centro de Ciências da Saúde, Santo Antônio de Jesus, \\ Bahia, Brasil. \\ *Endereço para correspondência: isabellamatos@ufrb.edu.br
}

\section{RESUMO}

A contínua intensificação da produção no setor avícola propicia condições favoráveis à ocorrência e à disseminação de alguns patógenos, como a Escherichia coli, que pode provocar infecções graves nos animais e no homem. O objetivo com este trabalho foi verificar a correlação existente entre a inspeção visual do fígado e a presença de Escherichia coli em fígados de frangos provenientes de matadouros avícolas. Para tanto, foram colhidas 62 amostras de fígados de frango, das quais $30 \mathrm{com}$ aspecto macroscópico inalterado e 32 com alteração macroscópica, que originou o descarte da carcaça pela inspeção da linha B. Escherichia coli foi isolada em $45,5 \%$ dos fígados coletados. A bactéria foi isolada em 18 amostras de fígados com aspecto macroscópico inalterado e nove amostras de fígados provenientes de carcaças que foram descartadas. A colangio-hepatite foi a alteração inflamatória predominante em 16/27 fígados e considerada multifocal em 15/16. Detectou-se a predominância de heterófilos e mononucleares (12/27). Os critérios de condenação das carcaças foram inadequados, haja vista a elevada presença de Escherichia coli nas amostras de fígados oriundos de carcaças consideradas próprias para o consumo humano, o que ressalta as diferenças encontradas nas análises microbiológicas e visuais. Diante dos resultados obtidos, torna-se necessária a continuidade dos estudos, especialmente quanto o potencial zoonótico da Escherichia coli e sua presença nos alimentos prontos para consumo.

Palavras-chave: avicultura, bacteriologia, inspeção, microbiologia, sanidade avícola.

\section{SUMMARY}

The continuous intensification of production in the poultry sector provides conditions that favor the occurrence and spread of some pathogens such as Escherichia coli, which can cause serious infections in animals and humans._The objective of this study was to verify the correlation between visual inspection of the liver and the presence of Escherichia coli in poultry livers from slaughterhouses. 62 liver chicken samples were collected from two slaughterhouses situated in the State of Bahia in July to August 2008. 30 livers were macroscopic unchanged and 32 showed macroscopic alterations that lead to carcass disposal for inspection of line B. Escherichia coli was isolated in $45.5 \%$ of livers collected. The bacterium Escherichia coli was isolated from 18 unchanged livers samples and nine from carcasses that were rejected. The cholangiohepatitis $(16 / 27)$ was predominant considering inflammatory alterations, and were considered multifocal in 15/16 livers. Heterophils and mononuclear cells were predominant (12/27). The criteria for condemnation of carcasses were inadequate, taking into consideration that pathogenic Escherichia coli were presented in apparently healthy animals, highlighting the differences found in the microbiological analysis and visual. Based on these results, it is necessary further studies, especially regarding the zoonotic potential of Escherichia coli and its presence in foods ready for consumption.

Keywords: aviculture, bacteriology, microbiology, poultry health, inspection. 


\section{INTRODUÇÃOO}

A importância da indústria avícola como fornecedora de proteína animal de baixo custo levou a criação de frangos de corte a ter impacto internacional. Os avanços na área de nutrição, genética, manejo e sanidade tornaram a avicultura a atividade pecuária de maior crescimento das últimas décadas (JACOBSEN \& FLÔRES, 2008).

A contínua intensificação da produção no setor avícola propicia condições que favorecem a ocorrência e a disseminação de patógenos, como a Escherichia coli, cujo agente etiológico possui amplo espectro de infecções invasivas nas espécies humana e de animais e se constitui um dos integrantes da microbiota intestinal de mamíferos e aves (RON, 2006).

Embora os relatos afirmem que o ambiente dos matadouros avícolas permite a instalação e a proliferação de Escherichia coli, poucos trabalhos têm sido desenvolvidos para esclarecer quais alterações anátomo-histopatológicas estão associadas à contaminação por esses micro-organismos. Não há certeza se frangos contaminados por enterobactérias são descartados, ao considerar as alterações macroscópicas do fígado no momento da inspeção (BARCELOS et al., 2006).

$\mathrm{O}$ veterinário oficial responsável pela Inspeção Federal, junto ao matadouro, se incumbe também, da missão de especificar a velocidade da nória na linha de evisceração, de maneira que, durante todo o abate, seja possível a normal realização dos exames post mortem. O fígado é inspecionado na Linha B, na etapa de evisceração, e os critérios de condenação de vísceras de frango, especialmente, do fígado consideram o aspecto visual (cor, forma e tamanho) e a consistência e odor do órgão (BRASIL, 1998).

O objetivo com este trabalho foi verificar a correlação existente entre a inspeção visual do fígado e a presença de Escherichia coli em fígados de frangos provenientes de matadouros avícolas.

\section{MATERIAL E MÉTODOS}

Nos meses de julho a agosto de 2008, foram colhidas aleatoriamente 62 amostras de fígados de frangos (Gallus gallus), provenientes de dois matadouros avícolas do Recôncavo baiano, sob fiscalização da Agência de Defesa Agropecuária da Bahia. Foram coletados 30 fígados com aspecto macroscópico inalterado e 32 fígados com alteração macroscópica, que originou o descarte da carcaça pela inspeção da linha B. As alterações visuais que resultaram no descarte da carcaça foram, a saber: septicemia (36\%), seguida por síndrome ascítica (26\%), colibacilose (19\%), caquexia (13\%) e aerossaculite $(6 \%)$.

Cada amostra foi constituída de um único fígado de frango, coletado na linha de inspeção com o auxílio do Fiscal Agropecuário Estadual. As amostras foram coletadas, assepticamente, com uma lâmina de bisturi, acondicionadas em recipientes estéreis, identificadas, refrigeradas e depois enviadas ao Laboratório de Microbiologia do Centro de Ciências da Saúde da Universidade Federal do Recôncavo da Bahia (UFRB), onde foram, imediatamente, executadas as análises microbiológicas e avaliação macroscópica.

As porções de cada amostra foram colocadas em frascos com formol tamponado, a $10 \%$, e enviadas ao Laboratório de Anatomia Patológica da Escola de Medicina Veterinária da 
Universidade Federal da Bahia (UFBA) para realização das análises histopatológicas.

Os parâmetros seguintes foram utilizados para descrição da macroscopia: coloração, superfície, tamanho, consistência e presença ou não de lesões no parênquima ao corte. Após essa etapa, as amostras foram fotografadas.

Fragmentos hepáticos, aparentemente, saudáveis, e áreas com lesões para a realização de cortes para análise histopatológica foram retirados das amostras, a totalizar 4 fragmentos por fígado. Estes foram fixados em formol tamponado, a $10 \%$, e preparados para inclusão em parafina. Em seguida, foram cortados em micrótomo ajustado para $5 \mu \mathrm{m}$ e os cortes obtidos corados pela hematoxilina-eosina (H-E). Duas seções histológicas foram examinadas sob microscopia de luz (BARCELOS et al., 2006).

Para pesquisa de Escherichia coli, cada amostra de fígado, cujo peso era de $1 \mathrm{~g}$, devidamente identificada, foi macerada e semeada em $9 \mathrm{ml}$ do caldo de infusão de cérebro coração, para posterior semeadura em Agar McConkey, pelo método de esgotamento, e incubada a $37^{\circ} \mathrm{C}$ durante $18 \mathrm{~h}$.

Transcorrido o tempo de incubação, colônias suspeitas de Escherichia coli pelas características coloniais típicas (colônias rosas-avermelhadas, lactose positivas) e morfotintoriais (bacilos Gram-negativos) foram transferidas com auxílio de agulha de platina para ágar nutriente para verificação de pureza e, posteriormente, para os meios bioquímicos.

Para a identificação da bactéria, foram utilizados os seguintes testes: produção de sulfeto de hidrogênio e fermentação da glicose, por meio do ágar tríplice açúcar-ferro, fermentação e oxidação da glicose, reação do citocromo oxidase, produção de fenilalanina desaminase, produção de indol, motilidade e produção de sulfeto de hidrogênio, com o Sulfeto Indol Motilidade, produção de urease, prova do vermelho de metila, prova do Voges-Proskauer e utilização de citrato e os tubos foram incubados a $37^{\circ} \mathrm{C}$ durante 24-48h. A leitura e interpretação das provas bioquímicas foram feitas de acordo com Koneman et al. (2008). Por fim, os dados foram tabulados por meio do programa estatístico SPSS (2008), versão 17 , e foi realizada análise descritiva.

\section{RESULTADOS E DISCUSSÃO}

Escherichia coli foi isolada em 45,5\% dos fígados coletados, dos quais 18 foram considerados com aspecto macroscópico inalterado (18/30) e nove foram descartados por septicemia (3/9), colibacilose (3/9), caquexia (2/9) e síndrome ascítica (1/9), o que sugere que a inspeção visual dos fígados no matadouro avícola não é suficiente para descartar carcaças contaminadas com Escherichia coli.

Um percentual menor foi observado por Barcelos et al. (2006), que avaliaram através da macroscopia, histopatologia e bacteriologia, fígados de frangos condenados no abate. Dos 100 fígados analisados por esses autores, isolou-se Escherichia coli em 21 amostras. Dos 10 fígados sem alterações coletados, houve o isolamento desta em 2 amostras. Miharro et al. (2001) isolaram a bactéria em 80,64\% (25/31) das amostras de carcaças de frangos condenadas por aerossaculite pelo Serviço de Inspeção Federal. Haider et al. (2004) isolaram em 96,66\% (29/30) das amostras provenientes de suabe intestinal de aves doentes ou mortas, e Silva et al. (2002) detectaram em 95\% das 60 amostras de frangos refrigerados, oriundas da cidade de João Pessoa, PB. 
Vale salientar que, no caso do estudo de Silva et al. (2002), as amostras foram carcaças de frangos, e a contaminação pode advir de outras fontes, como manipulação inadequada $\mathrm{e}$ equipamentos e utensílios contaminados. No estudo em questão, o microorganismo, possivelmente, contaminou a ave na granja, haja vista as lesões histopatológicas observadas.

Considerou-se que a presença do microorganismo nos fígados, aparentemente, sadios é preocupante, uma vez que o órgão está envolvido nas infecções hematógenas, por receber tanto sangue arterial, quanto sangue venoso do trato gastrintestinal. A infecção do fígado e a subsequente inflamação no órgão podem ser primárias, ou fazer parte de um processo sistêmico (MACLACHLAN \& CULLEN, 1998), como a infecção por Escherichia coli (RON, 2006).

Dentre os parâmetros macroscópicos observados, destaca-se a cor do fígado, que se constitui um parâmetro importante para detecção de patologias. A cor mais frequente das amostras, nas quais houve o isolamento de Escherichia coli, foi a castanho-escura (20/27), seguida da marrom-pálida (4/27) e esverdeada (3/27). Salienta-se que das 20 amostras com coloração castanho-escura, 18 eram provenientes de frangos considerados aptos para o consumo e dois eram de fígados oriundos de carcaças rejeitadas devido à caquexia. Cabe lembrar que a cor castanho-escura é a esperada para um fígado proveniente de um animal hígido.

Associadas às alterações geralmente difusas na coloração, foram observadas alterações macroscópicas que provavelmente contribuíram para que a carcaça fosse condenada, tais como: aumento ou diminuição de volume (5/27), áreas esverdeadas (4/27), focos necróticos (3/27), consistência friável (3/27) e espessamento das bordas (1/27), conforme a Figura 1 . O peso dos fígados variou de 36,26 a 53,84g, para os órgãos oriundos de carcaças consideradas aptas para o consumo e 19,14 a 77,22g, para os órgãos originários de carcaças rejeitadas.

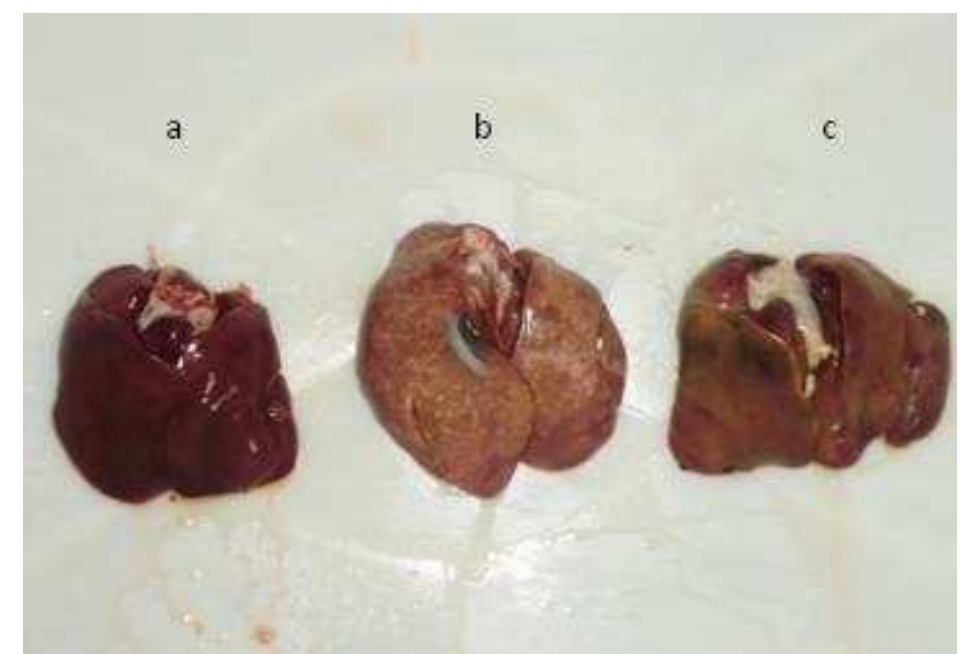

Figura 1. Fígados de frango provenientes de matadouro avícola da Bahia sob inspeção estadual. (a) Fígado macroscopicamente inalterado; (b) presença de focos necróticos, associada à condenação total da carcaça por Colibacilose; (c) presença de áreas esverdeadas, associada à condenação total por Septicemia 
Rev. Bras. Saúde Prod. Anim., Salvador, v.13, n.3, p.694-700 jul./set., 2012 http://www.rbspa.ufba.br ISSN 15199940

Resultados semelhantes foram encontrados por Dey et al. (2003) que também isolaram Escherichia coli em fígados provenientes de animais com septicemia/toxemia e observaram alterações macroscópicas, como aumento de volume, consistência friável, evidências de hemorragia e focos necróticos. Igualmente, Supartika et al. (2007) constataram que 89,59\% dos fígados estavam aumentados de tamanho, tinham uma consistência firme e mostravam múltiplos focos necróticos, de modo que a maior proporção estava contaminado com a bactéria.

Salienta-se que o volume de aves abatidas, diariamente, demanda dos serviços de inspeção maior número de profissionais que atuem na linha de produção. Nesse sentido, cabe destacar que algumas tarefas como a detecção de lesões do fígado são exclusivamente humanas, apesar da automatização dos processos industriais modernos.

Dentre os tipos de inflamação observados na microscopia, destacam-se a colangio-hepatite (16/27), seguida de pericolangite (7/27), colangite $(2 / 27) \mathrm{e}$ hepatite $(2 / 27)$. A lesão foi considerada multifocal em 22/27 fígados (15/16 amostras de colangio-hepatite) e focal em 5/27. O grau da lesão foi considerado moderado (16/27), discreto (6/27) e acentuado (5/27). Não houve diferença entre os que tinham ou não lesão macroscópica. O processo inflamatório era constituído pela associação de dois tipos celulares, principalmente, heterófilos e mononucleares (12/27), seguido por apenas heterófilos $(8 / 27)$ e apenas mononucleares (7/27), especialmente presente nos fígados com a presença de Escherichia coli. Salienta-se que nas amostras de fígados oriundos de carcaças que foram descartadas, a colangio-hepatite foi observada em 7/9 amostras e a lesão foi considerada multifocal em todos os casos (Figura 2). Dessas amostras, 4/9 apresentavam necrose, as quais foram caracterizadas como necrose de liquefação.

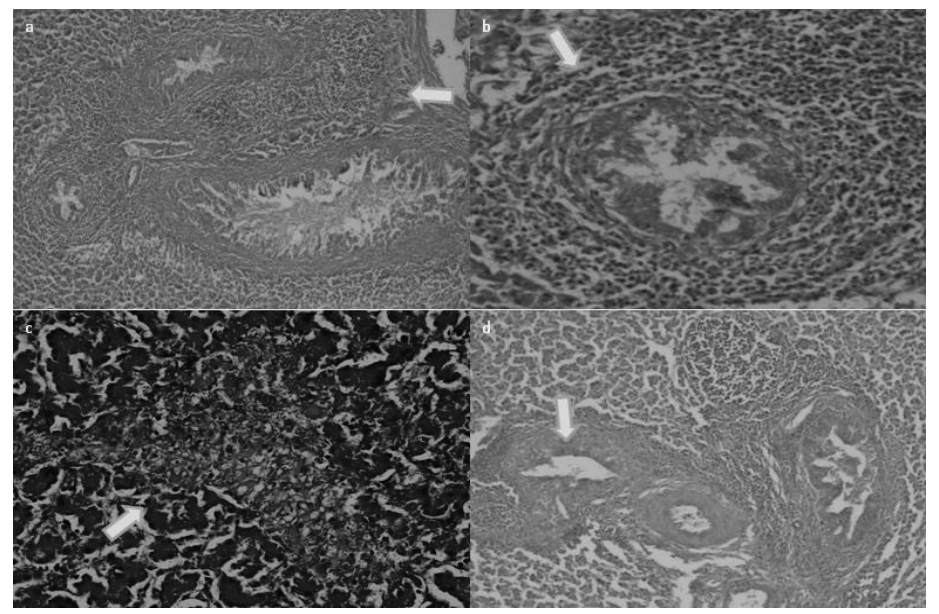

Figura 2. Fígado de frango com presença de Escherichia coli. (a) Colangite com presença de heterófilos e mononucleares. H-E, 110x. (b) Infiltrado mononuclear e hiperplasia periductal. HE, 430x. (c) Necrose liquefativa. H-E, 430x. (d) Microabscesso associado ao espaço porta e destruição da arquitetura ductal. H-E, 430x 
Esses dados corroboram com os achados de Barcelos et al. (2006) e Dey et al. (2003), que também observaram com maior incidência a colangiohepatite heterofílica multifocal, seguida de hepatite necrosante aleatória como achado microscópico associado ao isolamento de Escherichia coli. A presença de infiltrados mistos, especialmente heterófilos e linfócitos, associados à presença de Escherichia coli também foram encontrados por Haider et al. (2004). Apesar de não serem específicas, a colangio-hepatite e pericolangite com predominância de heterófilos podem estar associadas ao Clostridium perfringens, especialmente os sorotipos A e E, produtores de toxina $\alpha$ e $\alpha$ e $\beta$, respectivamente (SILVA et al. 2009). Lovland \& Kaldhusdal (2001) encontraram dados semelhantes em 33/45 amostras de fígados de frangos rejeitados no matadouro.

A congestão foi considerada discreta em $12 / 27$ fígados, seguida de moderada (9/27) e acentuada (6/27). A hemorragia foi observada em 3/27 amostras e necrose em $7 / 27$. A fibrose periportal ocorreu em 6/27 amostras e a hiperplasia dos ductos biliares em 9/27. Foram observados microabscessos em 9/27 amostras e 2/27 das amostras apresentavam esteatose. Como são consideradas alterações microscópicas inespecíficas, alguns desses achados foram semelhantes aos encontrados por Morais (2004), que realizou análise histológica e pesquisa de Aflatoxinas em aves.

Conclui-se que os critérios de condenação das carcaças utilizados foram inadequados, haja vista o índice elevado de isolamentos de Escherichia coli em fígados de frangos que foram liberados para consumo, ressaltando às diferenças encontradas nas análises microbiológicas e visuais. Diante dos resultados obtidos, torna-se necessário a continuidade dos estudos, especialmente quanto ao potencial zoonótico da Escherichia coli e sua presença nos alimentos prontos para consumo

\section{AGRADECIMENTOS}

À Coordenação de Aperfeiçoamento de Pessoal de Nivel Superior e a Universidade Federal do Recôncavo da Bahia pelo fomento de bolsa, à Dra. Marília Lima Costa da Agência de Defesa Agropecuária da Bahia e à Profa. Alessandra Estrela do Laboratório de Anatomia Patológica da Escola de Medicina Veterinária da Universidade Federal da Bahia pelo uso das instalações e auxílio técnico.

\section{REFERÊNCIAS}

BARCELOS, A.S.; FLÔRES, M.L.; KOMMERS, G.D.; NASCIMENTO, V.P.; SEGABINAZI, S.D.; ANTONIAZZI, T.; BASSAN, J.D.L. Macroscopia, histopatologia e bacteriologia de fígados de frangos (Gallus gallus) condenados no abate. Ciência Rural, v.36, n.2, p.561-567, 2006.

BRASIL. Ministério da Agricultura, Pecuária e Abastecimento. Portaria n.210, de 10 de novembro de 1998. Aprova o Regulamento Técnico da Inspeção Tecnológica e HigiênicoSanitária de Carne de Aves. Diário Oficial da República Federativa do Brasil, Brasília, DF, 26 nov. 1998. Disponível em:

$<$ http://extranet.agricultura.gov.br/sisleg is-consultarLegislacao.do>. Acesso em: 20 nov. 2008.

DEY, B.P.; CHEN, Y.R.; HSIEH, C.; CHAN, D.E. Detection of septicemia in chicken livers by spectroscopy. Poultry Science, v.82, p.199-206, 2003. 
Rev. Bras. Saúde Prod. Anim., Salvador, v.13, n.3, p.694-700 jul./set., 2012 http://www.rbspa.ufba.br ISSN 15199940

HAIDER, M.G.; HOSSAIN, M.G.; HOSSAIN, M.S.; CHOWDHURY, E.H.; DAS, P.M.; HOSSAIN, M.M. Isolation and characterization of Enterobacteria associated with health and disease in sonali chickens.

Bangladesh Journal of Veterinary Medicine, v.2, n.1, p.15-21, 2004.

JACOBSEN, G.; FLÔRES, M.L. Condenações por síndrome ascítica em frangos abatidos sob inspeção federal entre 2002 e 2006 no Estado do Rio Grande do Sul, Brasil. Ciência rural, v.38, n.7, p.1966-1971, 2008.

KONEMAN, E.W.; ALLE, N S.D.; JANDA, W.M.; SCHRECKENBERGER, P.C.; WINN, W.C. Diagnóstico microbiológico: texto e atlas colorido. 6.ed. Rio de Janeiro: Guanabara Koogan, 2008.

LOVLAND, A.; KALDHUSDAL, M.

Severely impaired production performance in broiler flocks with high incidence of Clostridium perfringens associated hepatitis. Avian Pathology, v.30, p.73-81, 2001.

MACLACHLAN, N.J.; CULLEN, J.M. Fígado, sistema biliar e pâncreas exócrino. In: THOMSON, R.G. (Ed.). Patologia Veterinária Especial. 2.ed. Porto Alegre: Artmed,1998. p.265-298.

MINHARRO, S.; LINHARES, G.F.C.; ANDRADE, M.A.; ROCHA P.T.; SANTANA A.P. Envolvimento de Escherichia coli, de Mycoplasma gallisepticum e de Mycoplasma synoviae em lesões de sacos aéreos em frangos abatidos no estado de Goiás. Ciência Animal Brasileira, v.2, n.2, p.111-117, 2001.
MORAES, L.B. Estabelecimento de escores histopatológicos de lesão hepática e determinação dos valores normais das enzimas aspartato aminotransferase e creatinina quinase em frangos de corte. 2004. 46p. Dissertação (Mestrado em Ciências Veterinárias) - Universidade Federal do Rio Grande do Sul, Porto Alegre.

RON, E.Z. Host apecificity of septicemic Escherichia coli: human and avian pathogens. Current Opinion in Microbiology, v.9, n.1, p.28-32, 2006.

SILVA, J.A.; AVERÊDO G.A.; BARROS C.M.R.; COSTA E.L.; FALCÃO M.M.S. Incidência de bactérias patogênicas em carne de frango refrigerada. Higiene Alimentar, v.16, n.100, p.97-101, 2002.

SILVA, R.O.S.; SALVARANI, F.M.; ASSIS, R.A.; MARTINS, N.R.S.; PIRES, P.S.; LOBATO, F.C.F. Antimicrobial susceptibility of Clostridium perfringens strains isolated from broiler chickens. Brazilian Jounal of Microbiology, v.40, p.262-264, 2009.

SUPARTIKA, I.K.E.; STROOMKRUYSWIJK, J.H; TOUSSAINT, M.J.M.; GRUYS, E. Necrotizing granulomatous hepatitis in slaughtered broilers. Avian diseases, v.51, n.2, p.632-638, 2007.

SPSS Inc. Statistical analysis using SPSS. Version 17. Chicago, 2008.

Data de recebimento: 18/10/2010

Data de aprovação: 02/04/2012 